九州大学学術情報リポジトリ

Kyushu University Institutional Repository

\title{
THE PHYLOGENY AND HIGHER CLASSIFICATION OF THE STAPHYLINIDAE AND THEIR ALLIED GROUPS (COLEOPTERA, STAPHYLINOIDEA)
}

Naomi, Shun-ichiro

https://doi.org/10.5109/2464

出版情報 : ESAKIA. 23，pp.1-27，1985-11-30. Entomological Laboratory，Faculty of Agriculture， Kyushu University

バージョン :

権利関係 : 
ESAKIA, (23) : 1-27. 1985

\title{
THE PHYLOGENY AND HIGHER CLASSIFICATION OF THE STAPHYLINIDAE AND THEIR ALLIED GROUPS (COLEOPTERA, STAPHYLINOIDEA) *
}

\author{
ShUN-ICHIRo NAOMI \\ Entomological Laboratory, Faculty of Agriculture, \\ Kyushu University, Fukuoka 812, Japan
}

\begin{abstract}
This paper deals with the phylogeny and higher classification of the Staphylinidae auct and their allied groups, i. e., Pselaphidae auct., Scaphidiidae auct., Scydmaenidae auct., Silphidae auct., and Catopiaria. The ground plan conditions of the Staphylinoidea are briefly described concerning the morphological characters useful for phylogenetic analysis. The phylogeny of the Staphylinidae and their allied groups is inferred, principally using the Hennigian method of phylogenetic analysis. Based on my phylogenetic study, a higher classification of the section Brachelytra is newly proposed.

The family Staphylinidae auct. is divided into three families, Oxytelidae sensu novo, Staphylinidae sensu novo, and Oxyporidae sensu novo. The Pselaphidae auct. are included in the Oxyporidae sensu novo. Accordingly, the section Brachelytra is classified into six families : Silphidae, Oxytelidae sensu novo, Staphylinidae sensu novo, Oxyporidae sensu novo, Scaphidiidae and Scydmaenidae.
\end{abstract}

\section{Introduction}

This is a case study of the phylogeny and higher classification of the Staphylinidae and their allied groups. The Staphylinoidea are one of the largest superfamilies of the order Coleoptera, comprising more than 40,000 species from all zoogeographical regions of the world except for the Antarctic. Of the members of the superfamily, the Staphylinidae auct. contain about 30,000 species belonging to about 20 good subfamilies, and many of subfamilies are characterized by credible autapomorphies. The component taxa (species, genera and tribes) of each subfamily of the Staphylinidae have remained nearly unchanged among the workers studying the Staphylinids. Interestingly, the Staphylinidae show morphological and ecological diversity to a surprising degree and retain a series of primitive conditions of morphological characters. These facts may suggest that the Staphylinidae are suitable for phylogenetic study at the higher level.

An aim of this study is to reconstruct the phylogeny of the Staphylinidae and their

* Contribution from the Entomological Laboratory, Faculty of Agriculture, Kyushu University, Fukuoka (Ser. 3, No. 181). 
allied groups as close as possible to their cladogenetic phenomena which had occurred once in the course of the evolution of the Coleoptera. For that purpose, the ground plan conditions of the morphological characters of the superfamily Staphylinoidea are inferred. And then, the phylogeny of the Staphylinidae and their allied groups is reconstructed with reference to the inferred ground plan conditions.

Not a few excellent monographs treating the Staphylinidae and their allied groups from various zoogeographical regions have been published in the last two hundred years. However, the higher classification systems at subfamily and family levels are not constant among the workers. For the higher classification of the Staphylinoidea, three different kinds of systems are employed today, namely, 1) the classical system supported by many European workers, 2) the French system supported by Paulian (1941), Jeanne1 and Jarrige (1949) and Coiffait (1972), and 3) the Lawrence-Newton system recently advocated by Lawrence and Newton (1982). As a result, it has become absolutely necessary to determine which system is in whole or in part acceptable from the phylogenetic viewpoint. In this paper, therefore, I have tried to solve this difficult problem based on a phylogenetic study, and then establish a higher classification of the Staphylinidae and their allied groups as reasonable as possible. This is the other aim of the present work.

However, the materials examined are insufficient in some cases for the inference of the polarities of character conditions. In this sense, the phylogeny and higher classification proposed in this paper are not meant to be the final result of the study of this field, but a scientifically documented basis for the phylogenetic systematics of the superfamily Staphylinoidea.

\section{Methods of Phylogenetic Analysis}

The phylogeny is a historical event which is not directly observable, so it can never be completely reconstructed even by using all the available recent and fossil specimens, whatever the group of organism is. Accordingly, the phylogeny of a group should be made public after it has been documented by any of the observable facts by which we can manage to approach at least indirectly its real picture, if it is studied under the name of science. The "facts" actually mean in many cases the particular conditions of "morphological" characters in the field of phylogenetics.

In order to find out the "facts" which are indispensable for the reconstruction of phylogeny, the Hennigian method of phylogenetic analysis $(1965,1966)$ was adopted in the course of this study. Essentially, I followed his method except for the following two aspects.

1. The "underlying autapomorphy" as well as the "autapomorphy" are adopted to define a group in question as the monophyletic. The concept of "autapomorphy" was proposed by Hennig. By definition, the "autapomorphy" is the presence of a character condition which is characteristic only for a particular group in all the component members of the group. The autapomorphic character condition is acquired by the ancestor of the group. On the other hand, the concept of "underlying autapomorphy" 
was recently proposed by 0 . A. Saether $(1979,1983)$ and used in his classification of the Chironomidae. The "underlying autapomorphy" is defined as the presence of a character condition which is characteristic only for a particular group in some or many of the component members of the group. In the typical pattern of "underlying autapomorphy", the primitive members show the primitive condition of the character in a group and its evolved members show the advanced condition (which is unique for the group). The underlying autapomorphic character condition occurs by parallelism only within the group.

2. In principle, the cladogram is pictured as a dichotomously branching dendrogram. However, the polychotomous branching is introduced into the cladogram when incongruence of the distributions of apomorphic character conditions is found among the three or more subgroups in question, by which the phylogenetic relationships cannot be depicted in the dichotomous way. In the cladograms, the relationships shown by the solid line were inferred by myself in this study, while those by the broken line were not studied or could not clarified by the present data.

For the determination of the relative primitive condition of a character, the outgroup comparison method of Watrous and Wheeler (1981) is adopted. In evaluating a character condition, "A condition is widely distributed" in the context simply means that "A condition is widely or extensively distributed in the groups in which it is observed". It does not mean that the criterion of "Common is primitive" of Crisci and Stuessy (1980) is adopted.

\section{Phylogenetic Analysis}

The phylogenetic relationships in the superfamily Staphylinoidea are discussed, paying special attention to the relationships in each of the Oxytelid-, Staphylinid- and Oxyporid-groups in this section.

The Oxytelid-, Staphylinid-, and Oxyporid-groups comprise the following 8, 14, and 11 subfamilies, respectively.

Oxytelid-group : Oxytelinae, Pseudopsinae, Osoriinae, Piestinae, Micropeplinae, Proteininae, Metopsiinae and Omaliinae.

Staphylinid-group : Tachyporinae, Phloeocharinae, Habrocerinae, Trichophyinae, Staphylininae, Xantholininae, Paederinae and Aleocharid-complex (= Hypocyptinae, Pygosteninae, Termitodiscinae, Trilobitideinae, Mimanommatinae, Trichopseniinae and Aleocharinae).

Oxyporid-group : Oxporinae, Megalopininae, Steninae, Euaesthetinae, Leptotyphlinae and Pselaphids (= Faroninae, Euplectinae, Batrisinae, Bythininae, Pselaphinae and Clavigerinae).

The above-mentioned three groups, Scaphidiidae and Scydmaenidae are grouped into "Staphylinida", new group name, in this paper.

Concerning the naming system of the pleuron and sternum of thorax, I followed Matsuda (1970). 


\section{Ground plan conditions of the morphological characters of the superfamily Staphylinoidea}

In this part, the ground plan conditions of the superfamily Staphylinoidea are inferred concerning the morphological characters useful for phylogenetic analysis. They will be discussed in more detail in the separate series of my papers entitled "The comparative morphology of the Staphylinidae and their allied groups". The ground plan conditions are as follows :

Body large, broad, subflat and strongly pigmented, without any modifications.

Head short and broad, without occipital constriction ; clypeofrontal region moderate in length and slightly narrowed anteriorly. Eyes situated behind the middle of head and moderate in size. Gula broad, with gular sutures distinct and running subparallel to each other. Tentorium with anterior, posterior and dorsal arms, laminatentorium, corpotentorium and posterior tentorial wall well developed, and with posterior and dorsal tentorial pits invisible.

Antennae 11-segmented, inserted on genal region, free, straight and filiform to submoniliform, without club at apex. Labrum transverse, glabrous or sparsely covered with short hairs, with its anterior margin nearly straight. Mandibles robust, broad, curved mesially before the middle and simply pointed at apices, without any teeth ; mandibular molas and prosthecae present. Maxillae with laciniae larger than galeae, moderate in size and broad-brush-shaped, with apical parts densely covered with moderately long hairs ; galeae situated just outside the laciniae, with apical parts furnished with moderately long hairs ; maxillary palpi 4-segmented, with 1st to 3rd segments baculiform and the 4th well developed. Labrum with submentum broadest at foremost part and narrowed posteriorly ; mentum trapezoidal and broader than long, with anterior margin straight ; ligula consisting of glossae and paraglossae in pairs ; labial palpi 3-segmented, with 3rd segments well developed, about an long as and a little thinner than the 2nd.

Cervix composed of three pairs of lateral sclerites, with 1st (basal) sclerites smaller than the 2nd (middle) ones.

Prothorax with anterior foramen small ; pronotum broad at base, with its posterolateral corner gently rounded and its posterior margin gently arcuate or nearly straight ; hypomera broad and smooth, without projection at inner margins ; plate composed of basisternum and preepisternum (hereinafter referred to as composite ventral plate) smooth, moderate in size and broad at sides ; procoxal cavities situated before the middle of prothorax, broad and open behind. Mesothorax with pleural sutures distinct ; composite ventral plate smooth ; regions around the mesothoracic spiracles membranous; mesocoxal cavities broad and separated to each other. Metathorax with anterior intercoxal process broad; anapleural crefts distinct ; anepisterna and epimera present ; composite ventral plate smooth. Metendosternite with furcal arms separated to each other and without basal stalk.

Elytra elongate oval, broad at base, pointed at apex and covering wholly the abdomen, with their lateral to hind margins being continuous. Legs with metacoxae 
oblong triangular and subflat to subconical ; meso- and metatrochanters subconical and short ; femora nearly straight and baculiform ; tibiae thin and sparsely covered with short hairs at apical halves, without any modifications such as projection and ctenidium ; tarsal formula 5-5-5 ; claws being 2 in number in a leg and symmetrical.

Abdomen with 3 rd to 7 th segments subequal in length to one another without any sculptural modifications ; 3rd sternum with a basomedian longitudinal ridge ; lateral plates (= paratergites) being in a pair in each of 1 st to 7 th segments ; stigmata situated on the membranous region between terga and lateral plates in 3rd to 6th segments ; 9th tergum consisting of an unpaired plate and dorsal in position, without any modifications ; ventral struts of 9th tergum running parallel and separated to each other in male, or not present in female ; 9th sternum consisting of one plate with posterior margin smooth in male ; 9th sternum consisting of hemisternites, coxites and styli in pairs, with posterior margins of coxites smooth in female ; 10th tergum moderate in size, with posterior margin gently rounded ; defense and adoption glands not developed. Male genitalia with median lobe symmetrical with its basal part small and membranous to weakly sclerotized, and with its apical part elongate and moderately sclerotized ; parameres consisting of a pair of simple and symmetrical stalks, without any modifications at apical parts ; armatures of internal sac composed of hairs or short setae. Spermatheca in female being membranous.

\section{M embers, autapomorphy and underlying autapomorphy of the section Catopiaria, with discussion on the systematic position of the family A gyrtidae}

The Catopiaria are composed of six families in Japan : Clambidae, Dasyceridae, Ptiliidae, Leiodidae, Catopidae and Agyrtidae. According to Jeanne1 and Jarrige (1949), the family Leptinidae, which is not found in Japan, also belongs to this section. Concerning the Limulodidae, I was unable to correctly determine their systematic position in the Staphylinoidea. But judging from the prothoracic structure described by Seevers and Dybas (1943), they may be related to the Ptiliidae. So the Limulodidae are treated as a member of this section in this paper. Consequently, the section Catopiaria consists of the following eight families : Clambidae, Leptinidae, Dasyceridae, Limulodidae, Ptiliidae, Leiodidae, Catopidae and Agyrtidae.

Jeanne1 and Jarrige defined the Catopiaria by possession of the dorsally attached condition of the parameres to the median lobe in male aedeagus. According to my observation, however, the parameres in the Catopiaria are certainly visible from dorsal side, but not necessarily attached dorsally. Rather, they are often connected laterally with the median lobe, or sometimes ventrally. And the structure of male aedeagus is generally more primitive in the Catopiaria than in the Brachelytra. So by the parameral condition adopted by Jeannel and Jarrige, the Catopiaria cannot be defined as a monophyletic group. According to Lawrence and Newton (1982), there is no derived condition at adult stage, by which the Catopiaria are considered to be monophyletic. However, one underlying autapomorphic character condition is detected as follows : Tentorium composed only of the anterior and posterior arms. In many 
Catopiaria, the dorsal tentorial arm is completely lost or obliterated. The lost condition of dorsal tentorial arm is also found in the Staphylinida such as the Aleocharinae, but obviously attained through parallel evolution. The autapomorphy in the strict sense of Hennig is not present for the Catopiaria.

The Agyrtid-group has hitherto been considered a member of the family Silphidae. However, the morphological resemblances by which the Agyrtid and the other groups of the Silphid have been thought to be closely related, are based on symplesiomorphies. And, the above-mentioned tentorial condition is shared between the Agyrtid and the other members of the Catopiaria, indicating that the inclusion of the Agyrtid into the Catopiaria seems to be reasonable. The genus Camiolium was once considered as a member of Agyrtid-group. But in this genus, the tentorium is composed of the dorsal and posterior tentorial arms without anterior arm, clearly demonstrating that this should not be included in the Agyrtidae, but in the Oxytelid-group.

In the Catopiaria, there appears to be a tendency of the body to become smaller and more convex in the order of the Agyrtidae, Catopidae, Leiodidae and the other groups of the Catopiaria. The relatively large $(5-8 \mathrm{~mm})$ and subflat to moderately convex bodies found in the Agyrtidae are primitive conditions within the Catopiaria. And the Catopiaria except for the Agyrtidae are characterized by the following credible autapomorphic character condition : Inner hypomeral projection and furcasternum of prothorax being nearly to completely amalgamated into a plate to form the bottom of the procoxal cavity. Judging from the above data, the Agyrtidae are thought to be the remotest group within the Catopiaria, namely, the intermediate group between the primitive Silphidae and the higher Catopiaria (Fig. 1). The monophyly of the Agyrtidae is not clarified based on the present data.

III. M embers, autapomorphy and underlying autapomorphy of the section Brachelytra, with discussion on the systematic position of the family Silphidae

Thy phylogeny of the Brachelytra was firstly studied by Sharp and Muir (1912) exclusively based on the morphology of male aedeagus. They concluded that the Staphylinidae, Pselaphidae, Scaphidiidae and Scydmaenidae are closely related to one another and originated from the lower Silphidae in which the Bathysciinae are most primitive. By Jeanne1 and Paulian(1944), the above-mentioned five families were included in the section Brachelytra based on the morphology of male aedeagus, elytra and so on. Later, Jeanne1 and Jarrige (1949) reclassified the Brachelytra into eight families : Silphidae, Scaphidiidae, Pselaphidae, Scydmaenidae, Aleocharidae, Oxytelidae, Stenidae and Staphylinidae, making reference to the Paulian higher classification (1941) of the Staphylinoidea.

The component members of the section Brachelytra in this paper are equal to those proposed by Jeanne1 and Paulian (1944) as a whole. However, the classification of the Brachelytra into subgroups here is different from that by them. Namely, the members of the Brachelytra are classified into six groups : Silphidae, Oxytelid-, Staphylinid- and Oxyporid-groups, Scaphidiidae and Scydmaenidae, of which the last 
PHYLOGENY AND HIGHER CLASSIFICATION OF THE STAPHYLINOIDEA

Section

Catopiaria

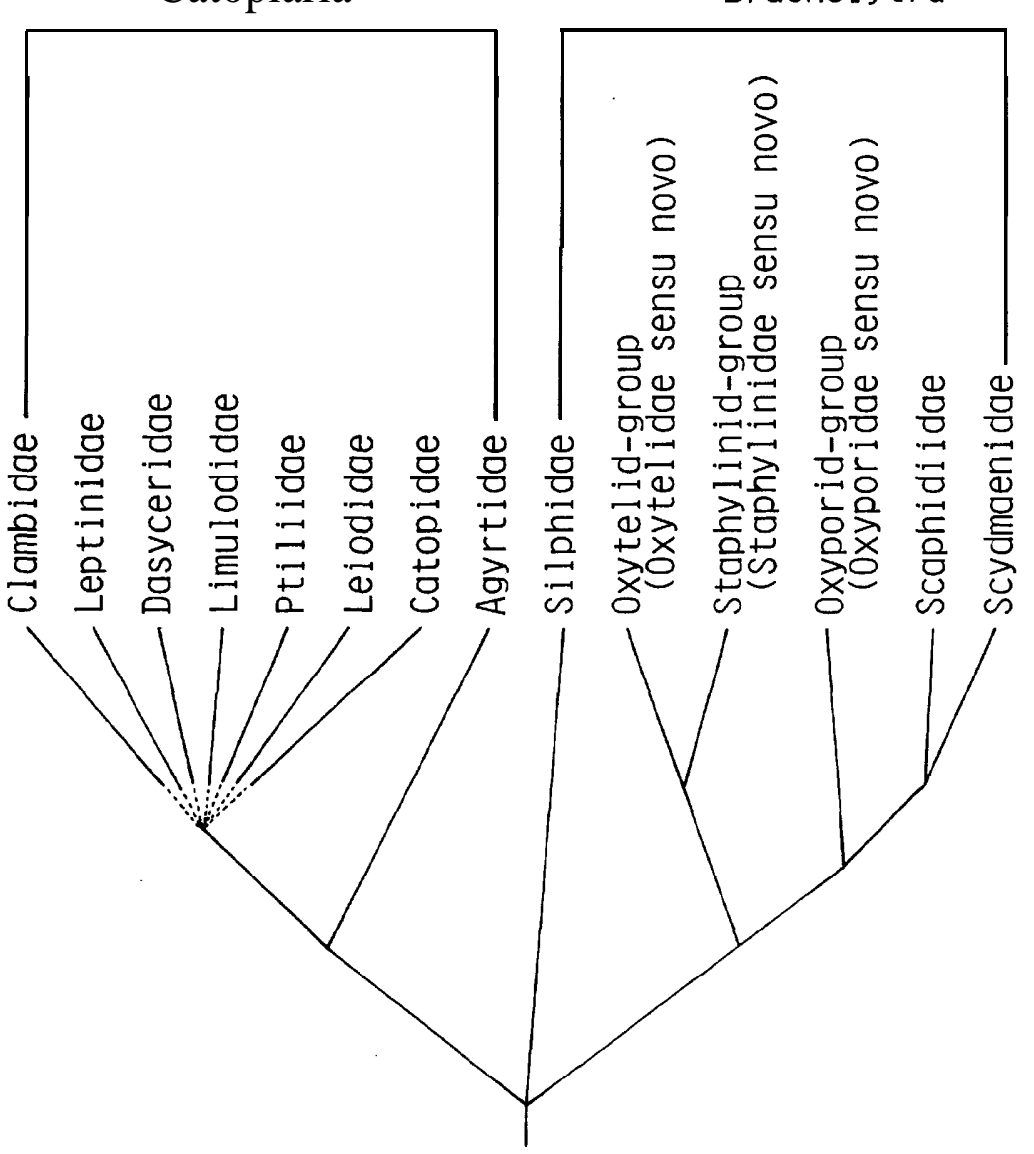

Fig. 1. Phylogenetic relationships in the superfamily Staphylinoidea.
Section

Brachelytra

five groups compose the Staphylinida.

The synapomorphic character conditions for the members of the Staphylinida are enumerated as follows :1) Basal part of median lobe being bulbous and more or less sclerotized and 2) stigmata on 3rd to 8th abdominal segments situated on the corresponding tergal plates. These two synapomorphies are thought to be highly credible to define the Staphylinida as a monophyletic group, because they do not or very rarely occur in the Silphidae and Catopiaria. On the other hand, most of the Silphidae show primitive conditions concerning nearly all of the characters examined, so that the Silphidae are not characterized by apomorphic condition. A few derived conditions are present in this family such as peculiar antennal club, elytral marking, enlargement of hind femur and so on, but they are observed at the species or genus level. And the Silphidae do not share any apomorphic conditions with the Staphylinida. As a result, no autapomorphy and underlying autapomorphy can be detected for the Brachelytra. 
The systematic position of the Silphidae in the Staphylinoidea is different according to authors. For example, besides Sharp and Muir, Jeanne1 and Jarrige (1949) considered that the Silphidae are more closely related with the Scaphidiidae than with the other members of the Brachelytra. Lawrence and Newton (1982) treated the Silphidae as a member of their staphylinine group.

In addition to the above-mentioned information on the nature of the Silphidae, the following lines of evidence are recognized to infer the systematic position of the Silphidae in the Staphylinoidea. Firstly, the Silphidae do not share apomorphic conditions with the Catopiaria as well as Staphylinida, and retain such plesiomorphic character conditions as the transverse mesothoracic presternum and relatively large 1 st abdominal sternum. Secondly, some morphoclines are observable continuously from the Silphidae to the higher Catopiaria and to the higher Staphylinida, for example, on the shape of body and the structure of male genitalia. And their polarities of primitiveness are always present in the Silphidae. So it can be inferred that the Silphidae are most primitive within the Staphylinoidea, but their members are varied and always slightly morphologically specialized from the stem species of the whole Staphylinoidea. The Catopiaria and Staphylinida are, without doubt, evolved from the Silphid-type ancestor as already pointed out by Sharp and Muir. And a member of the Silphidae might be recognized as the stem-species of the whole Staphylinoidea, if plenty of fossil specimens could be extensively studied. This type of evolution cannot be analyzed by the Hennigian method. Consequently, the cladogenetic phenomena among the Catopiaria, Silphidae and Staphylinida cannot be depicted in the form of dichotomy, but of trichotomy. Such a primitive group as the Silphidae is regarded as "holarchaic group" in this paper.

The reason why the Silphidae belong to the Brachelytra is practically based on the symplesiomorphy observed in the Silphidae and Staphylinida excluding the Pselaphids, Aleocharinae, and many Oxytelid-group in the tentorial condition : Anterior, posterior and dorsal arms well developed. And it is also on the fact that the intermediate conditions of the shape of body between the Silphidae and the higher Staphylinida are found in the primitive members of the Oxytelid-group such as Apatetica, Nodynus, Brathinus, Camiolium, Trigonodemus and some other Omaliinae.

\section{Phylogenetic relationships among five component groups of the Staphylinida}

1. Phylogenetic relationship between two supragroups of the Staphylinida. In the Staphylinida, two supragroups are recognized. The 1st supragroup consists of the Oxytelid- and Staphylinid-groups and the 2nd one consists of the Oxyporid-group, Scaphidiidae and Scydmaenidae (Fig. 1).

The 1st supragroup is monophyletic by reason of only one underlying autapomorphic character condition : Elytra being short and not extending posteriorly beyond the 3rd abdominal tergum. In the primitive members of the Piestinae and Omaliinae, the elytra are elongate, and sometimes wholly cover the abdomen. The short condition of the elytra independently occurs in the Oxyporid-group.

The 2nd supragroup is considered to be monophyletic based on the following 
autapomorphic character conditions $(1,2)$ and underlying autapomorphic character condition (3) :1) Body 'being strongly convex, or subcylindrical to cylindrical, 2) mentum about as long as broad, and 3) antenna possessing a loose club. Contrarily, the body (1) is moderately convex through subflat to very flat in the Oxytelid- and Staphylinid-groups except for Osorius and Bledius in which it is cylindrical. The shape and structure of the clubs in the antennae (3) are diversified within the Oxyporid-group, Scaphidiidae and Scydmaenidae, and the primitive Oxyporinae bear no antennal clubs.

The Staphylinida are a monophyletic group based on the two apomorphic conditions as mentioned above in III. Considering this evidence, it is inferred that these two supragroups of the Staphylinida are considered as sister-groups.

2. Phylogenetic relationship between the Oxytelid-and Staphylinid-groups. The autapomorphy of the Oxytelid-group is difficult to detect, but the monophyly of this group is determined by the following three underlying autapomorphic character conditions :1) Antenna being not free and inserted under the anterolateral border of epicranium, 2) tentorium composed of dorsal and posterior arms, and anterior arm being completely to nearly lost, and 3) dorsal structural modifications developed on head, pronotum and elytra. The 1 st condition is not developed in the primitive Omaliinae. The similar condition to the 1st independently occurs in some Paederinae and Oxyporinae, in which the anterolateral border of epicranium is only weakly developed. The 2nd condition is observable in the majority of the Oxytelid-group, but the anterior arm is more or less developed in some primitive members. The lost condition of anterior tentorial arm is independently developed in the Scaphidiidae and higher members of the Oxyporid-group. Concerning the 3rd condition, the horns are present on head and/or pronotum in some Piestinae, Osoriinae and Oxytelinae. The longitudinal costae and sulci are often present on head, pronotum and elytra in the Piestinae, Micropeplinae, Pseudopsinae and Oxytelinae. On the contrary, modifications of the same quality very rarely occur in the Staphylinid- and Oxyporid-groups except for the paederine genus Myrmecosaurus. The presence of these dorsal modifications deserve to be one of the characteristics of the Oxytelid-group.

The monophyly of the Staphylinid-group is difficult to clarify. In the majority of the Staphylinid-group, the lateral plates of abdomen are usually two paired in each of 3rd to 6th segments, while in the Oxytelid-group excluding the Oxytelinae, they are usually in a pair. Although the former condition is paralleled in the Oxyporinae and Megalopininae, it is probably regarded as the underlying autapomorphy of the Staphylinid-group.

As the monophyly of the group consisting of the Oxytelid- and Staphylinid-groups was clarified in IV-1, it is inferred that the Oxytelid-group has a sister-group relationship with the Staphylinid-group based on the above-mentioned evidence.

3. Phylogenetic relationships among the Oxyporid-group, Scaphidiidae and Scydmaen idae. The monophyly of the Oxyporid-group is supported by the following autapomorphic character conditions $(1,2)$ and underlying autapomorphic character condition (3) : 1) Elytra being short and not extending beyond 3rd abdominal tergum, 2) mandibular mola completely lost, and 3) mandibular prostheca absent. The 2nd 
condition independently occurs in the higher members of the Staphylinid-group. The 3rd condition is distributed in the Oxyporid-group excluding the Oxyporinae and Leptotyphlinae. In the Oxytelid- and Staphylinid-groups, the prostheca is well retained. The absent condition of the prostheca deserves to be one of the characteristics for the Oxyporid-group.

The synapomorphic character conditions $(1,2)$ and underlying synapomorphic character condition (3) for the group consisting of the Scaphidiidae and Scydmaenidae are as follows :1) Metendosternite being Y-shaped, with its basal stalk short, 2) procoxa short and ovate, and 3) bottom of procoxal cavity more or less developed and composed of furcasternum, or furcasternum plus inner hypomeral projection. The similar condition to the 1 st is independently developed in the higher members of the Oxyporid-group. The 3rd condition is paralleled in the remote Catopiaria.

The Scaphidiidae are regarded as a monophyletic group by reason of the following autapomorphic character conditions : 1) Maxillary galea well developed and larger than lacinia, with hairs on the apical part ; the hairs being of the same length and dense so that the apices of hairs form the extremely smooth convex surface, 2) posteromedian margin of pronotum narrowly produced posteriorly to form a subtriangular to semicircular projection, and 3) 3rd abdominal sternum being extraordinarily large and much longer than the others. In my opinion, the peculiar fusiform body of the Scaphidiid-group may have been evolved in accordance with the enlargement of 3rd abdominal sternum, although no change has occurred in the size of the 3rd abdominal tergum. The reason why the 3rd sternum only is evolved so much cannot be clarified from the viewpoint of functional morphology, but this peculiar condition is undoubtedly considered to be a credible autapomorphy for the Scaphidiidae.

The autapomorphic character conditions for the Scydmaenidae are as follows :1) Maxillary galea and lacinia provided with small numbers of thick and long setae at apices, 2) one or two pairs of large foveae present at the base of pronotum, 3) bases of both pronotum and elytra well constricted, and 4) pro-, meso- and metafemora moderately to strongly swollen at their distal halves. The 2nd condition is independently developed in the Euaesthetinae and so on.

Based on these facts, the phylogenetic relationships among these three component groups are inferred as follows. The Scaphidiidae and Scydmaenidae form a monophyletic group which has a sister-group relationship with the Oxyporid-group.

\section{V.Members of the Oxytelid-group and their phylogenetic relationships}

The Oxytelid-group consists of three subgroups : Omaliinae- Piestinae- and Oxytelinae-subgroups. The Omaliinae-subgroup includes four subfamilies : Omaliinae, Micropeplinae, Proteininae and Metopsiinae. The Piestinae-subgroup includes two subfamilies : Piestinae and Osoriinae. And the Oxytelinae-subgroup includes two subfamilies : Oxytelinae and Pseudopsinae. The phylogenetic relationships in each of three subgroups of the Oxytelid-group are discussed below, but the relationships among three subgroups cannot be inferred based on the present data. The phylogenetic relationships of the subfamilies of the Oxytelid-group are illustrated 


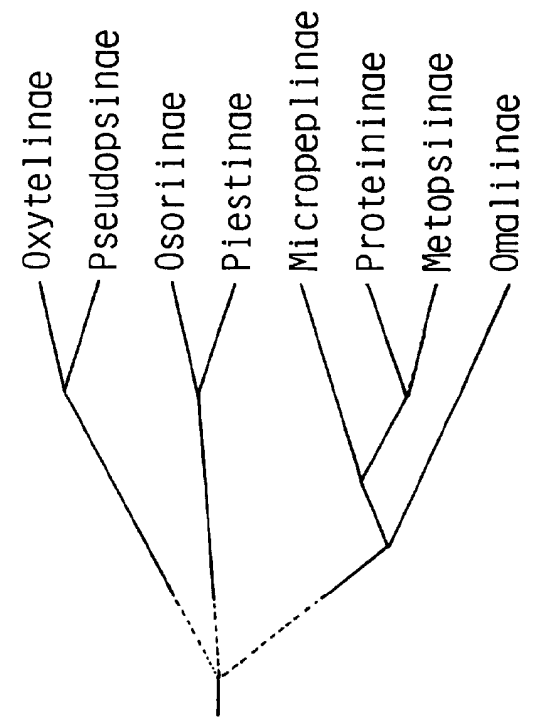

Fig. 2. Phylogenetic relationships in the subfamilies of Oxytelid-group (=Oxytelidae sensu novo).

in Fig. 2.

1. Omaliinae-subgroup. This subgroup is well characterized by the elongate-oval body, presence of ocellus (Metopsiinae and Omaliinae), and relatively elongate elytra, all of which are, however, plesiomorphic conditions. This subgroup is the most primitive of three subgroups of the Oxytelid on these bases, but insufficiently characterized by only one underlying autapomorphic character condition : Defense gland developed on the posteromedian part of 8th abdominal sternum. The gland is not present in the Micropeplinae. Information on this gland is not available for the Metopsiinae.

For the Omaliinae, one autapomorphic character condition is detected as follows : Anterior margin of 9th sternum connected with the ventral struts of 9th tergum which are fused mesially. The monophyly of the group consisting of the Micropeplinae, Proteininae and Metopsiinae is supported by the following two autapomorphic character conditions :1) Second and 3rd segments of maxillary palpus thick or swollen, the 3rd broad at base, and the 4th longer and slender than the 3rd and 2) posterolateral corner of pronotum being minutely and abruptly incised. A similar condition to the 1 st is independently developed in the remote Leptotyphlinae.

The Micropeplinae are well characterized by the following ten autapomorphic character conditions : 1) Posterior tentorial pit very large and deeply concave, 2) antenna g-segmented with the last segment forming a very large subspherical club, 3) lacinia relatively long with 5 to 7 robust setae at apex, 4) apical part of galea spherical with hairs regularly arranged in 7 to 9 rows, 5) pronotum impressed with small numbers of cells enclosed by costae, 6) prothoracic hypomeron with a broad furrow, 7) composite ventral plates of meso- and metathoraxes provided with many shallow 
impressions, 8) each of pro-, meso- and metatibiae provided with a small spine at the ventral margin in male, 9) tarsal formula 4-4-4, and 10) 4th to 7th abdominal terga and sterna with peculiar longitudinal carinae.

The synapomorphic character condition for the Metopsiinae and Proteininae is detected as follows : Meso- and metatibiae in male bearing a series of blackish minute setae on the ventral margins. This condition is highly credible to link these two subfamilies. Two autapomorphic character conditions for the Proteininae are present : 1) Ninth tergum composed of a pair of plates and situated ventrally and 2) coxites of 9th sternum in female small and fused into a short cylindrical structure, and its apex provided with a pair of small styli. And for the Metopsiinae, one credible autapomorphic character condition is detected : A small emargination present between the basal portion of antenna and the anterior margin of eye.

In considering the above-mentioned facts, the phylogenetic relationships of the subfamilies of the Omaliinae-subgroup are inferred as follows. The Metopsiinae and Proteininae form a monophyletic group which has a sister-group relationship with the Micropeplinae. And the Omaliinae have a sister-group relationship with the group consisting of the Micropeplinae, Proteininae and Metopsiinae. Some modern Coleopterologists give a family rank to the subfamily Micropeplinae mainly because of their peculiar shape of body and their g-segmented antenna, but this taxon is treated as a subfamily belonging to the Oxytelid-group in this paper based on the abovementioned phylogenetic relationships.

2. Piestinae-subgroup. The monophyly of the Piestinae-subgroup is based on the following two underlying autapomorphic character conditions :1) Anterior foramen of pronotum being very broad and 2) lateral plates of abdomen completely absent. The 1st condition is present in the Piestinae-subgroup except for Apatetica and Nodynus. The 2nd condition is found in the Piestinae (Eleusini, Thoracophorini, Leptochirini, Lispini) and the Osoriinae (Osoriini). On the other hand, the lateral plates are present in the various degrees in the Piestinae (Piestini and Trigonurini). The lost condition of lateral plates is paralleled in Hypostenus, Palaminus and so on.

There is probably no problem concerning the monophyly of the Piestinae-subgroup based on these two underlying autapomorphies, although Bernhauer and Schubert (1911) placed the Osoriinae just after the Oxytelinae in their Coleopterorum Catalogus. The problem rather arises from the classification of the above-mentioned seven tribes into two subfamilies : Piestinae and Osoriinae. In the classical system, the Osoriinae include only the Osoriini and the other six tribes are treated as the members of Piestinae. Blackwelder (1942), however, transferred the four tribes Lispini, Leptochirini, Thoracophorini and Eleusini to the Osoriinae mainly because these four tribes and the Osoriini have the lost condition of abdominal lateral plates in common. Freude, Harde and Lohse (1964) followed Blackwelder system.

In my view, the Osoriini are, without doubt, considered to be monophyletic by reason of the following ten credible autapomorphic character conditions :1) Body cylindrical, 2) posterior walls of tentorium fused mesially in accordance with the gular sutures being confluent, 3) antenna strongly geniculate, 4) mentum longer than broad 
and shallowly wholly depressed, 5) submentum being transverse and broadened posteriorly, 6) lacinia setaceous, 7) setaceous denticles regularly arranged in a row along the outer margins of pro- and mesotibiae in both sexes, 8) 9th sternum reduced or absent, 9) paramere of male aedeagus absent, and 10) spermatheca in female spherical. In these respects, the Osoriini are exceedingly remote from the other six tribes of the Piestinae-subgroup. On the other hand, the six tribes except for the Osoriini have subflat to very flat body in common and most of them live under bark.

Judging from these facts, the followings are inferred. Firstly, the lost condition of the lateral plates of the abdomen adopted by Blackwelder can be considered the underlying aut apomorphy for the Piest inae-subgroup as mentioned above. Secondly, the six tribes excluding Osoriini may form a natural group although the credible synapomorphy is not detected for them based on the present data. And thirdly, there may be two directions in the course of the evolution of the Piestinae-subgroup : Body becoming flat in the six piestine tribes, or cylindrical in the Osoriini. So, I tentatively support the classical system concerning the tribal classification of the Piestinae and Osoriinae and conclude that the Piestinae may have a sister-group relationship with the Osoriinae.

3. Oxytelinae-subgroup. The genus Pseudopsis was placed next to the Micropeplinae by Bernhauer and Schubert (1910) and next to the Leptochirini by Cameron (1930) without stating any reasons. Herman (1975) thought that Pseudopsis and the Oxytelinae are considered to be sister-groups by reason of his synapomorphic character condition : Presence of the exit of defence glands on the 9th abdominal tergum. The systematic position of Pseudopsis in the Staphylinida had been unstable among workers as already mentioned, but it is always considered as a member of the Oxytelid-group. And every author regarded Pseudopsis as the member of monogeneric Pseudopsinae (or Pseudopsini). On the other hand, Newton (1982) concluded in redefining the subfamily Pseudopsinae that four genera Nanobius, Asemobius, Zalobius and Pseudopsis belong to the Pseudopsinae by possession of the synapomorphies : Presence of a stridulatory file on the side of 9th abdominal tergum, and so on. And then he suggested that the sister group of his Pseudopsinae may be "sought among the Phloeocharinae or allied subfamilies (Tachyporinae, Trichophyinae and Habrocerinae)“. In determining the sister-group of his Pseudopsinae, he seems to emphasize the importance of the hypopharyngeal resemblance observed in Pseudopsis and some Phloeocharinae, and to think that the synapomorphy adopted by Herman is not credible enough to link the Pseudopsinae (sensu Newton) and the Oxytelinae as sistergroups because that derived condition is not found in Nanobius, Asemobius and Zalobius.

Nanobius, Asemobius and Zalobius are considered the members of the Pseudopsinae in addition to Pseudo\&is, because of the presence of the credible synapomorphies for them detected by Newton. In my opinion, however, the carinate or costate condition of the pronotum and elytra universally found in all the genera of the Pseudopsinae is, without doubt, a characteristic of the Oxytelid-group, demonstrating that the Pseudopsinae (sensu Newton) belong to that group. For the Oxytelinae, there 
are present two underlying autapomorphic conditions as follows : 1) Tarsal formula 3-3-3 and 2) lateral plates of abdomen being in two pairs in each of the 3rd to 7th segments. And the Herman's synapomorphy for Pseudopsis and the Oxytelinae can be newly interpreted as the underlying synapomorphy for the Pseudopsinae (sensu Newton) and Oxytelinae. So it may be inferred that the Oxytelinae-subgroup consisting of the Pseudopsinae (sensu Newton) and Oxytelinae is monophyletic and these two component subfamilies are sister-groups.

VI. Members of the Staphylinid-group and their phylogenetic relationships, with note on the parallelism between the Aleocharinae and the Oxytelinae

The Staphylinid-group consists of three subgroups : Tachyporinae-, Aleocharinae-, and Staphylininae-subgroups. The Tachyporinae-subgroup contains only one subfamily : Tachyporinae. The Aleocharinae-subgroup contains seven subfamilies : Hypocypt inae, Pygosteninae, Termitodiscinae, Trilobitideinae, Mimanommatinae, Trichopseniinae and Aleocharinae. And the Staphylinid-subgroup contains six subfamilies : Phloeocharinae, Habrocerinae, Trichophyinae, Staphylininae, Xantholininae and Paederinae. The phylogenetic relationships of the subfamilies of the Staphylinidgroup are illustrated in Fig. 3.

1. Tachyporinae-subgroup. Tichomirova (1968) described three fossil genera,

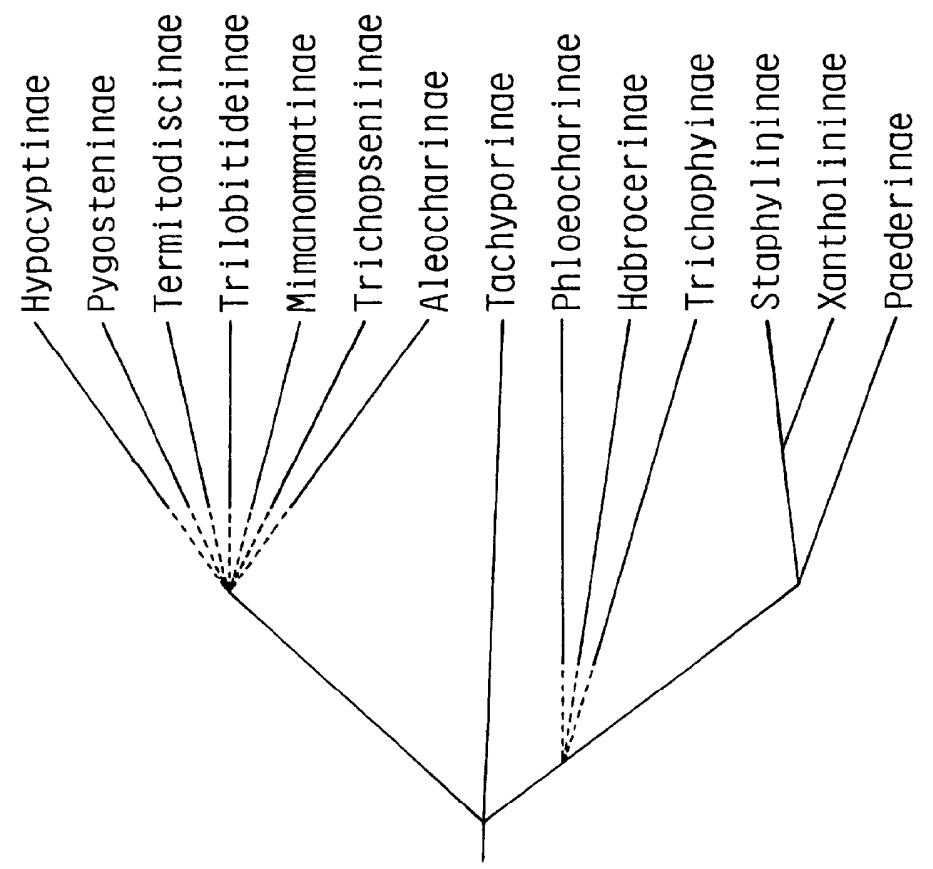

Fig. 3. Phylogenetic relationships in the subfamilies of Staphylinid-group (= Staphylinidae sensu novo). 
Mesotachinus, Tachyporoides and Abscondus belonging to the Tachyporinae from the late Jurassic Kara Tau beds. Comparing the morphological characters described on these fossil specimens with those of recent specimens, they are highly similar to each other. And the main morphological structures of the body are relatively homogeneous and no drastic structural modifications are found in the members of the recent Tachyporinae. So it may be inferred that the members of the Tachyporinae have been evolved only slightly in fundamental structures from their ancestor over a long period of about 200 million years. In the Tachyporinae, there are found the plesiomorphic persistance of the clear midcranial suture of head (Tachyporus and Tachinus), the hypomeron of pronotum producing ventrolaterally and elongate elytra (all the members of the Tachyporinae), and the beltlike 10th abdominal sternum (Lordithon). And the derived conditions of morphological characters are rarely present on some parts such as protibiae, abdominal stigmata (atrophy) and 8th abdominal segment. These indicate that this subfamily is most primitive (holarchaic) in the Staphylinid-group.

2. Aleocharinae-subgroup. The monophyly of this subgroup is supported by the following credible autapomorphic character condition : Paramere of male aedeagus on one side being tripartite into basal stalk, median and apical plates, with median plate lamellar and moderately sclerotized. This peculiar parameral condition is universally distributed within this subgroup as far as I could examine, and the similar condition is only found in some Oxytelinae. In this sense, this subgroup is so homogeneous that it is treated as "Aleocharid-complex" in this paper. The phylogenetic relationships among the subfamilies of the Aleocharinae-subgroup cannot be clarified based on the present data. For the subfamily Aleocharinae only, the autapomorphic character conditions are detected as follows :1) Tentorium composed only of anterior and posterior tentorial arms and laminatentorium, 2) composite ventral plate of prothorax very narrow or strongly constricted at sides, 3) hind margin of elytron sinuate, 4) elytra short and reaching only the posterior margin of 1st abdominal segment and 5) presence of abdominal defence gland with its opening situated at the basal margin of 7 th sternum.

3. Staphylininae-subgroup. The autapomorphy and underlying autapomorphy for this subgroup cannot be detected based on the present data, but the morphoclines are clearly present in this subgroup (the morphoclines are mentioned in the latter). These morphoclines reveal that the Phloeocharinae, Habrocerinae and Trichophyinae possess the intermediate conditions between the primitive Tachyporinae and the higher members of the Staphylinid-group concerning some morphological characters.

The monophyly of the group consisting of the Staphylininae, Xantholininae and Paederinae is supported by possession of the following five autapomorphic character conditions: 1) Head being broadest at foremost part with clypeofrontal region very broad, 2) occiput strongly to very strongly constricted, 3) mandibular mola obsolete or absent, 4) lacinia large and broad-brush-shaped, with dense hairs at apical margin and 5) mesocoxal cavities large, broad, shallow and continuous to each other. The monophyly of each of the subfamilies Paederinae, Staphylininae and Xantholininae is clarified as follows. For the Paederinae, three underlying autapomorphic character 
conditions are present :1) Presence of abdominal gland with its opening situated at the basal margin of 4th sternum, '2) dorsal part of median lobe submembranous to membranous, and 3) armatures of internal sac composed of a few large spines. These character conditions are usually found in the higher groups of this subfamily. For the Staphylininae, two credible underlying autapomorphic character conditions are detected : 1) Parameres of male aedeagus fused into an elongate stalk and 2) apex of the fused paramere of male aedeagus provided with black small sensory tubercles. And for the Xantholininae, three underlying autapomorphic character conditions are present :1) One or two pairs of sulci being present on clypeofrontal region, 2) 1st cervical sclerite very large and broader than the 2nd, and 3) mandible strongly robust, broad and very slightly curved before the middle.

The following evidence is recognized to infer the phylogenetic relationships among the three subfamilies. The similarities are found between the Staphylininae and the Xantholininae :1) Antenna inserted on clypeal region just behind the mandible, 2) labrum provided with long or very long hairs, 3) metendosternite possessing the posterolateral arm and 4) all the tibiae setaceous. On the other hand, the Xantholininae share the small condition of 10th abdominal tergum with the Paederinae. The following similarities are also observed between some Xantholininae and Paederinae : 1) Region around the mesothoracic spiracle moderately sclerotized and 2) protibia provided with ctenidia on ventrolateral side. Concerning the 1 st similarity, the manner of the sclerotization varies at the genus level in these two subfamilies. A similar condition to the 2 nd is independently but frequently developed within the superfamily Caraboidea. Furthermore, the Staphylininae share the falciform condition of mandible with the Paederinae. The phylogenetic relationships among these three subfamilies are difficult to infer due to the complex parallelism mentioned above, but it is inferred that the occurrences of the similarities observed between the Staphylininae and the Xantholininae are based on synapomorphies. Therefore, it is considered that the Staphylininae and Xantholininae form a monophyletic group which has a sister-group relationship with the Paederinae.

Coiffait and Saiz (1968) treated the South American tribe Amblyopinini as a subfamily probably because of their singular biology, namely, parasitism on mammals. In this tribe, the parameres of male aedeagus are fused into an elongate stalk, and its apex is provided with the blackish sensory tubercles on the undersurface. These conditions are shared between the Amblyopinini and the other tribes of the Staphylininae. In addition, they are similar to one another in the general shape of the body. Judging from the data mentioned above, the tribe Amblyopinini is nothing but a member subordinate to the subfamily Staphylininae. As already pointed out by Seevers (1955) who is a specialist of the Amblyopinid-group, this tribe is considered to be the closest relative to the Quediini.

4. Phylogenetic relationships among three subgroups of the Staphylinid-group. A set of morphoclines are found from the Tachyporinae to the Aleocharinae as follows : 1) Shape of body changing from fusiform through elongate to variously constricted types, 2) 4th segment of maxillary palpus becoming more subulate, 3) elytra becoming 
shorter, and 4) metacoxa becoming more quadrangular and lamellar. Concerning the 1st morphocline, the Hypocyptinae, Pygosteninae, Termitodiscinae, Trilobitideinae, Oligotini, Leucocraspedini, Myllaenini and Tachyporinae retain the fusiform condition of body. In the most advanced subfamily Aleocharinae, the shape of body is usually elongate, but shows surprising variations due to the development of the constrictions and expansions of the various parts of body. Concerning the 3rd morphocline, the elytra usually extend to the apex of the 3rd abdominal tergum in the Tachyporinae, while they cover only the 1st abdominal tergum in the Aleocharinae.

The other set of morphoclines are found from the Tachyporinae to the Paederinae : 1) Shape of body changing from fusiform through elongate to linear types, 2) position of eye transforming from the middle to the anterior parts of the head, 3) occipital constriction becoming stronger. Concerning the 1st morphocline, in addition to the Tachyporinae, the Habrocerinae and Atanygnathini retain the fusiform condition of body. The conditions of the shape of body in the Trichophyinae and Phloeocharinae are intermediate between the fusiform and the elongate types. The higher Staphylinidgroup such as the Staphylininae, Xantholininae and Paederinae has the elongate to linear bodies. Concerning the 3rd morphocline, the occiput is indefinitely constricted in the Tachyporinae, while in some higher-Paederinae, it is strongly constricted to the extent of being about $1 / 6$ times as broad as head.

It should be noted that the polarities of primitiveness in these morphoclines are always found in the Tachyporinae. When considering the presence of the abovementioned morphoclines instead of synapomorphy and underlying synapomorphy for any two subgroups of the Staphylinid-group, their phylogenetic relationships are not clarified by the Hennigian method. As a result, it is inferred that these three subgroups of the Staphylinid-group may have been evolved trichotomically from a Tachyporinaelike ancestor.

5. Parallelism between the Oxytelinae and the Aleocharinae. The Oxytelinae and Aleocharinae are the most derived subfamilies in the Oxytelid- and Staphylinidgroups, respectively. Parallelism is observed between some Oxytelinae and the Aleocharinae concerning the following four characters :1) Elytra, 2) 3rd abdominal sternum, 3) 9th abdominal sternum and 4) paramere of male aedeagus. The parallel conditions are as follows :1) Elytra being very short and covering only the 1st abdominal tergum, 2) basomedian longitudinal ridge of 3rd sternum absent, 3) 9th sternum more or less fused with 9th tergum in female and 4) paramere lamellar. In the Aleocharinae, the paramere on one side is generally completely tripartite with its median plate lamellar, while in the Oxytelinae it is not or only obscurely tripartite, and the apical half of the paramere is more or less lamellar. It is astonishing to find that the above-mentioned parallelism occurs in such a precise manner between such remote groups.

\section{Members of the Oxyporid-group and their phylogenetic relationships, with discussion on the systematic position of the Pselaphids}

The Oxyporid-group consists of the Oxyporinae, Megalopininae, Steninae, 
Euaesthetinae, Leptotyphlinae, Faroninae, Euplectinae, Batrisinae, Bythininae, Pselaphinae and Clavigerinae. The latter six subfamilies form the so-called Pselaphids. The Oxyporid-group cannot be divided into the subgroups. The phylogenetic relationships among the subfamilies are depicted in the form of an asymmetrical cladogram as in Fig. 4.

1. First cleavage between the Oxyporinae and the other groups of the Oxyporid. The monophyly of the Oxyporinae is supported by reason of the following five autapomorphic character conditions : 1) Clypeofrontal region very short (about $1 / 15$ the length of head), 2) each of 4th to 10th antennal segments with the flat lateral dilation before the middle, 3) under surface of left mandible provided with a moderate and pointed tooth near the middle, 4) lacinia large with very sparse short hairs on its inner margin, and 5) mentum with a pair of flat projections at the middle of anterior margin. The Oxyporinae are probably remote from the other members of the Oxyporid-group and primitive when considering the presence of such plesiomorphic conditions as the antenna not clavate, the procoxal cavity very broad and situated before the middle of prothorax, and the mesocoxae broadly separated by the metathoracic intercoxal process.

The following derived conditions are widely distributed among ten subfamilies of the Oxyporid-group except for the Oxyporinae : 1) Prothoracic composite ventral plate large and long, 2) procoxal cavity very narrow and situated behind the middle of prothorax, and 3) mesocoxal cavity situated mesially, narrow and deep. On the other hand, the Oxyporinae and Megalopininae are similar to each other in the following points :1) Third segment of labial palpus being large and broader than the 2nd, 2)

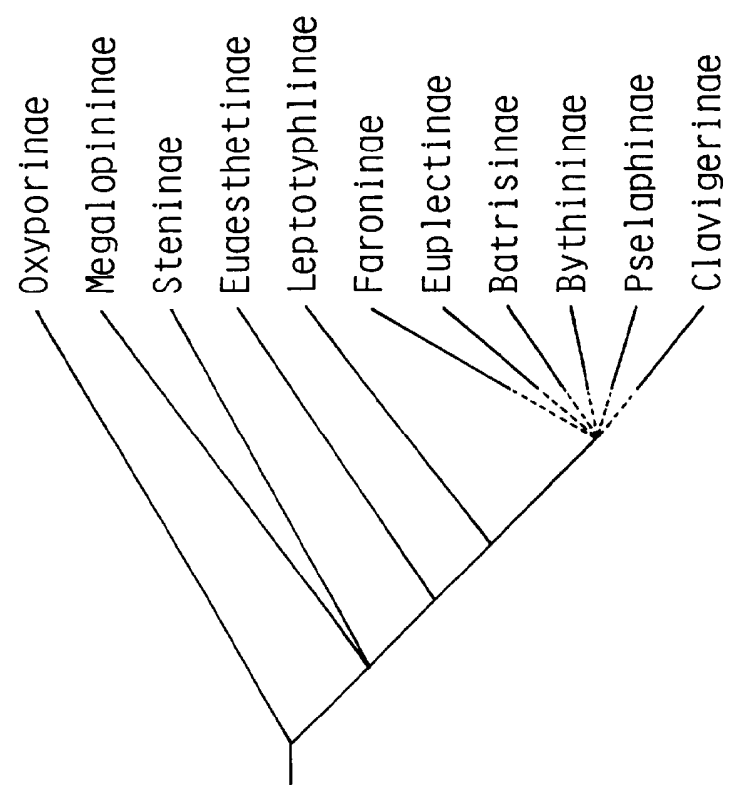

Fig. 4. Phylogenetic relationships in the subfamilies of Oxyporid-group (=Oxyporidae sensu novo). 
metendosternite Y-shaped with median process, and 3) two pairs of lateral sclerites in each of 3rd to 7th abdominal segments. But the following differences are present between these two subfamilies concerning the 1st and 2nd points. The 3rd labial palpal segment (1) is truncate at the apex in the Oxyporinae, while it is pointed in the Megalopininae. The median process of metendosternite (2) is pointed in the Oxyporinae, while it is bifurcate at the apex in the Megalopininae. It is difficult to determine which group of character conditions, the former three or the latter three, reflects the true cladogenesis. But it is inferred that the occurrences of the former three conditions found in the Oxyporid-group except for the Oxyporinae are based on synapomorphies and the latter three conditions between the Oxyporinae and the Megalopininae are brought about by parallel evolution. Therefore, the Oxyporinae have a sister-group relationship with the other groups of the Oxyporid-group.

2. Second cleavage among the Megalopininae, Steninae and the group consisting of the Euaesthetinae, Leptotyphlinae and Pselaphids. The monophyly of the Megalopininae is supported by a series of credible autapomorphic character conditions :1) Dorsal surface of head sparsely and irregularly covered with medium-sized foveae, 2) antenna with last 3 segments forming a loose club and with its last segment furnished with long hairs, 3) labrum long with a deep and broad emargination at the middle of anterior margin, 4) pronotum with transverse and longitudinal depressions whose bottoms are sparsely covered with large punctures, 5) posterior $2 / 3$ of mesothoracic composite ventral plate covered with large foveae, 6) apex of metathoracic intercoxal process being bifurcate and 7) 3rd to 7th abdominal terga and sterna provided with reversed V-shaped sculptures. For the Steninae, the following four autapomorphic character conditions are detected :1) Antenna inserted a little behind the anterior margin of eye, 2) eye very large and convex, nearly or wholly occupying the side of head, 3) presence of abdominal gland with its opening at the apical margin of 10th tergum and 4) posterior margin of 9th sternum in male and posterior margin of coxite of 9th sternum in female being minutely serrate.

The monophyly of the group consisting of the Euaesthetinae, Leptotyphlinae and Pselaphids is clarified by possession of the autapomorphic character conditions (1-4) and underlying autapomorphic character condition (5):1) Dorsal tentorial pit being distinctly recognizable from the exterior, 2) 2nd segment of labial palpus being much thicker than the 3rd, with a very long bristle or bristles at anterolateral side, 3) number of tarsal segments decreasing (Euaesthetinae : 5-5-4 and 4-4-4; Leptotyphlinae and Pselaphids : 3-3-3 and 2-2-2), 4) body weakly pigmented and 5) pleural suture obliterated or absent in mesothorax.

The following evidence permits me to infer the phylogenetic relationships among the Megalopininae, Steninae and the group consisting of the Euaesthetinae, Leptotyphlinae and Pselaphids. The Steninae, Euaesthetinae and Pselaphids are similar to one another in the galea and lacinia of maxilla being of the same size, short and broad, and the metendosternite being simple and V-shaped. The Steninae, Euaesthetinae and Leptotyphlinae have a resemblance to one another in the 4th segment of the maxillary palpus subulate. On the other hand, the Megalopininae are similar to the Steninae as 
follows :1) Ligula bearing a pair of bundles composed of the membranous lobes at anterolateral corners and 2) 3rd antenna1 segment long and slender. The membranous lobes (1) in the Megalopininae are longer than those in the Steninae. A similar condition to the 2nd is devoloped in Acrotrichis, the Scaphidiidae and Stenaesthetini. Furthermore, the Steninae are similar to the Euaesthetinae in the falciform mandible, and to the Stenaesthetini in the shape of the head. The phylogenetically important conditions of the above-mentioned morphological characters are so complexly distributed among the Megalopininae, Steninae and the group consisting of the Euaesthetinae, Leptotyphlinae and Pselaphids that it was not determined which similarities are based on synapomorphies. Consequently, the phylogenetic relationships among these three groups cannot be depicted by dichotomy but by trichotomy.

3. Phylogenetic relationships among the Euaesthetinae, Leptotyphlinae and Pselaphids. The Leptotyphlinae are considered as a monophyletic group based on the following two autapomorphic character conditions : 1) Compound eye absent and 2) maxillary palpus with 2nd and 3rd segments very large and subspherical and the 4th short and thin, For the Euaesthetinae, only one autapomorphic character condition is detected as follows : Tarsomeres of metaleg being 4 in number.

The Pselaphids are well characterized by the following many autapomorphic character conditions (1-5) and underlying autapomorphic character ones (6-11). 1) Dorsal tentorial pit weakly to strongly concave, 2) gular sutures completely fused into a line, obliterated or absent, 3) anapleural cleft of metathorax absent, 4) metepimeron reduced and weakly sclerotized, 5) two or three pairs of foveae situated at the base of elytra, 6) maxillary palpus 5-segmented, 7) meso- and metatrochanters elongate, 8) claw 1 in number in a leg, 9) 4th abdominal segment very large in the Pselaphids excluding the Faroninae and Euplectinae, 10) 9th and 10th abdominal segments reduced or absent and 11) adoption glands developed on various parts of abdomen. On these bases, the Pselaphids are, without doubt, considered to be monophyletic. And they share the synapomorphic character condition (1) and underlying synapomorphic character conditions (2-6) with the Leptotyphlinae as follows : 1) Tarsal formula 3-3-3 and $2-2-2,2)$ mandible relatively short, with 4 to 6 small teeth at inner side, 3) labial palpus 4-segmented, 4) apical part of median lobe of male aedeagus reduced or absent, 5) paramere of male aedeagus asymmetrically developed and 6) internal armatures of male aedeagus composed of twig-shaped structures and exposed. Therefore, it is inferred that the Pselaphids and Leptotyphlinae consists of a monophyletic group which has a sister-group relationship with the Euaesthetinae.

4. Systematic position of the Pselaphids. The Pselaphids have a unique appearance due to the peculiar shape and structure of the head, antenna and mouthparts as well as the eleven derived conditions mentioned above. So, most of workers, even the ciadists, have firmly believed for a long time that the Pselaphids form a good family in the Staphylinoidea and their closest relative is the whole Staphylinidae. Only Crowson $(1938,1955)$ suggested correctly that the Pselaphids are closely related with the Steninae and Euaesthetinae based on his study of the metendosternite of the Coleoptera. As discussed above in considerable detail, it was clarified soundly that the 


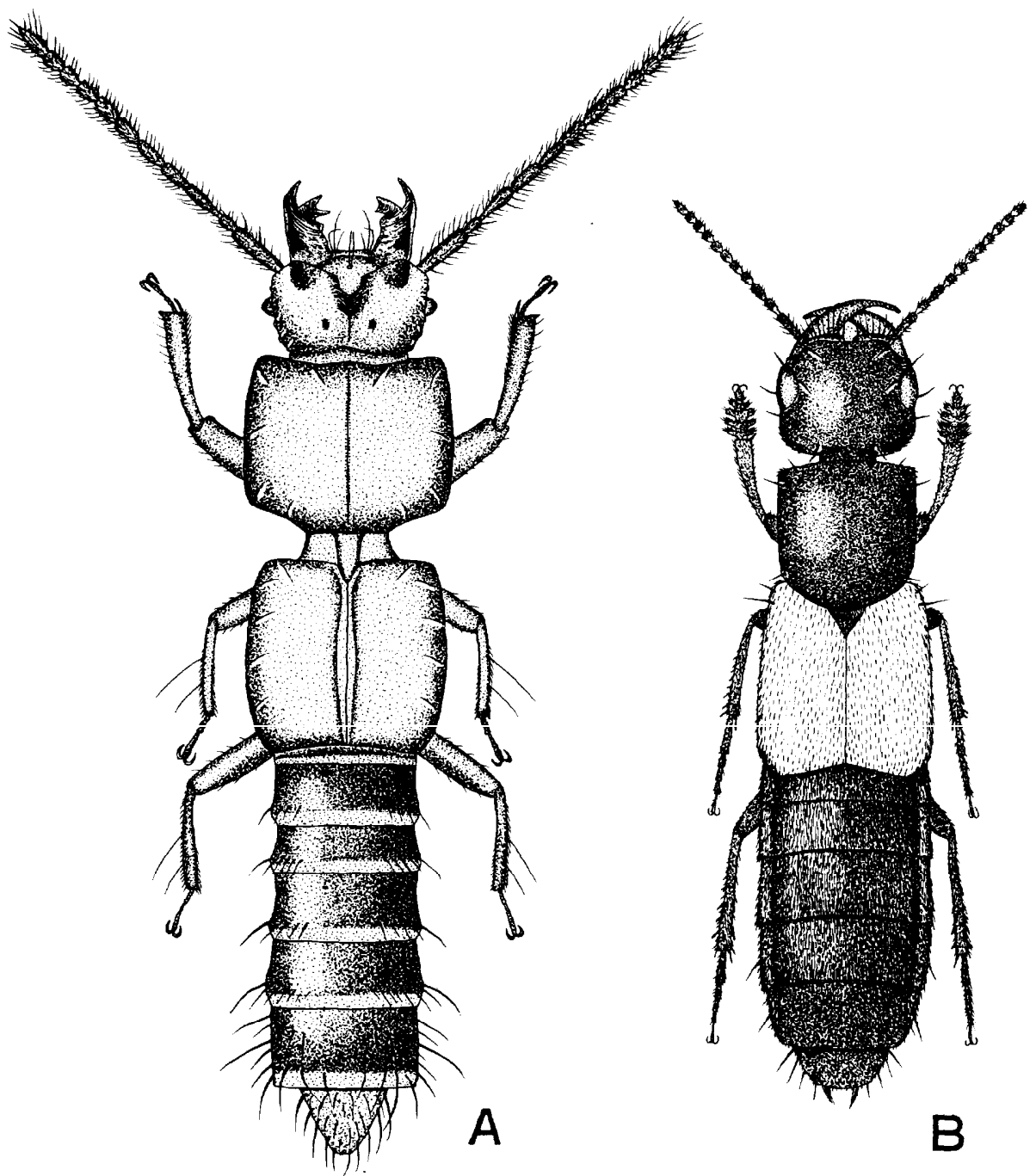

Fig. 5. A :Priochirus sp. (subfamily Piestinae) ; B :Phucobiusdensipennis Bernhauer, 1931 (subfamily Staphylininae)

Pselaphids and Leptotyphlinae are sister-groups. Therefore, the Pselaphids cannot be treated as an independent family, but as subordinate groups to the Oxyporid-group from a viewpoint of phylogenetic systematics. The taxonomic treatment of the Pselaphids in the Staphylinoidea will be referred to again in the next section. The phylogenetic relationships withisn the Pselaphids were not studied in this paper.

\section{$H$ igher Classification}

In this section, the higher classification systems of the Brachelytra are discussed, 
giving special attention to the Oxytelid-, Staphylinid- and Oxyporid-groups. Three different systems of the higher classification of the Brachelytra proposed by previous workers are mentioned, and each is separately evaluated from the viewpoint of phylogenetic systematics. And then a higher classification system is proposed based on the results of my phylogenetic analysis.

\section{Higher classification systems of the Brachelytra proposed by the previous workers}

The higher classification of the Brachelytra proposed by many authors from the beginning of 19th century is classified into the classical, French and Lawrence-Newton systems.

1. Classical system. In the classical system of the Brachelytra, the following five families, i.e., Silphidae, Scaphidiidae, Scydmaenidae, Pselaphidae and Staphylinidae each are treated as an independent family. Concerning the Staphylinidae, Erichson (1839-1840) published an excellent monograph dealing with the genera and species of the Staphylinidae known from the world at that time. This system has been persistently adopted with slight modification over a long term of years by the succeeding workers.

The arrangement of component members in this system usually begins with the Micropeplinae and ends with the Aleocharinae, or vice versa. The component subfamilies may be arranged in this system as follows : Micropeplinae, Piestinae (Fig. 5,A), Pseudopsinae, Phloeocharinae, Proteininae, Metopsiinae, Omaliinae, Oxytelinae, Osoriinae, Leptotyphlinae, Oxyporinae, Megalopininae, Steninae, Euaesthetinae, Paederinae, Xantholininae, Staphylininae (Fig. 5,B), Habrocerinae, Trichophyinae, Termitodiscinae, Pygosteninae, Tachyporinae, Hypocyptinae, Trilobitideinae, Mimanommatinae, Trichopseniinae and Aleocharinae.

In this arrangement, the 8 subfamilies from the Micropeplinae to the Osoriinae excepting the Phloeocharinae are equivalent to the members of my Oxytelid-group (Table 1). The 5 subfamilies from the Leptotyphlinae to the Euaesthetinae are included in my Oxyporid-group. And the 14 subfamilies from the Paederinae to the Aleocharinae and the Phloeocharinae are equivalent to the members of my Staphylinid-group. It is my opinion that the overall similarities of the shape and color of the body play the decisive roles in the arrangement of the component groups of the Staphylinidae in the classical system.

The genus Bledius is usually placed behind in order in the list of the Oxytelinae. The Osoriinae are classified next to the Oxytelinae. And then the Leptotyphlinae, Oxyporinae and Megalopininae follow in order. All these groups except for the Leptotyphlinae show the long and cylindrical (or thick) condition of the body, which is rarely found in the Brachelytra. Based on this overall similarity, these groups are thought to be related in the classical system. However, the similarity of cylindrical body between Bledius and the Osoriinae has been brought about by parallel evolution, while the occurrence of this condition among the Oxyporid-group, Scaphidiidae and Scydmaenidae is based on synapomorphy. So the character independently occurring 
Table 1. Comparison of the higher classification systems of the Brachelytra.

\begin{tabular}{|c|c|c|c|}
\hline Classical System ${ }^{(1)}$ & Naomi System & French System $^{(2)}$ & $\begin{array}{c}\text { Lawrence-Newton }^{(3)} \\
\text { System }\end{array}$ \\
\hline Silphidae & Silphidae & Silphidae & $\begin{array}{l}\text { Omaliine group } \\
\text { Omaliinae }\end{array}$ \\
\hline Staphylinidae & Oxytelidae & \multirow{2}{*}{ Scaphidiidae } & Microsilphinae \\
\hline Micropeplinae & Oxytelinae & & Empelinae \\
\hline Piestinae & Pseudopsinae & \multirow[t]{2}{*}{ Pselaphidae } & Neophoninae \\
\hline Pseudopsinae & Osoriinae & & Proteininae \\
\hline Phloeocharinae & Piestinae & \multirow[t]{2}{*}{ Scydmaenidae } & Dasyceridae \\
\hline Proteininae & Micropeplinae & & Micropeplidae \\
\hline Metopsiinae & Proteininae & \multirow{2}{*}{ Oxyporidae } & \multirow[t]{2}{*}{ Pselaphidae } \\
\hline Omaliinae & Metopsiinae & & \\
\hline Oxytelinae & \multirow{2}{*}{ Omaliinae } & (Aleocharomorpha) & \multirow{2}{*}{$\begin{array}{l}\text { Tachyporine group } \\
\text { Pseudopsinae }\end{array}$} \\
\hline Osoriinae & & Micropeplidae & \\
\hline Leptotyphlinae & Staphylinidae & Stenidae & Phloeocharinae \\
\hline Oxyporinae & Tachyporinae & Oxytelidae & Tachyporinae \\
\hline Megalopininae & Phloeocharinae & Tachyporidae & Trichophyinae \\
\hline Steninae & Habrocerinae & Trichophyidae & Habrocerinae \\
\hline Euaesthetinae & Trichophyinae & Habroceridae & Aleocharinae \\
\hline Paederinae & Staphylininae & \multirow{3}{*}{$\begin{array}{l}\text { Hypocyptidae } \\
\text { Aleocharidae }\end{array}$} & \\
\hline Xantholininae & Xantholininae & & \multirow{6}{*}{$\begin{array}{l}\text { Oxyteline group } \\
\text { Piestinae } \\
\text { Osoriinae } \\
\text { Oxytelinae } \\
\text { Scaphidiidae }\end{array}$} \\
\hline Staphylininae & Paederinae & & \\
\hline Habrocerinae & Hypocyptinae & (Staphylinomorpha) & \\
\hline Trichophyinae & Pygosteninae & \multirow{4}{*}{$\begin{array}{l}\text { Staphylinidae } \\
\text { Leptotyphlinae } \\
\text { Euaesthetinae } \\
\text { Paederinae }\end{array}$} & \\
\hline Termitodiscinae & Termitodiscinae & & \\
\hline Pygosteninae & Trilobitideinae & & \\
\hline Tachyporinae & Mimanommatinae & & \multirow{4}{*}{$\begin{array}{l}\text { Staphylinine group } \\
\text { Oxyporinae } \\
\text { Megalopsidinae } \\
\text { Steninae }\end{array}$} \\
\hline Hypocyptinae & Trichopseniinae & Xantholininae & \\
\hline Triiobitideinae & Aleocharinae & \multirow[t]{2}{*}{ Staphylininae } & \\
\hline Mimanommatinae & & & \\
\hline Trichopseniinae & Oxyporidae & & Euaesthetinae \\
\hline \multirow[t]{2}{*}{ Aleocharinae } & Oxyporinae & & Leptotyphlinae \\
\hline & Megalopininae & & Paederinae \\
\hline \multirow[t]{2}{*}{ Pselaphidae } & Steninae & & Staphylininae \\
\hline & Euaesthetinae & & Scydmaenidae \\
\hline \multirow[t]{2}{*}{ Scaphidiidae } & Leptotyphlinae & & Silphidae \\
\hline & Faroninae & & \\
\hline \multirow[t]{7}{*}{ Scydmaenidae } & Euplectinae & & \\
\hline & Batrisinae & & \\
\hline & Bythininae & & \\
\hline & Pselaphinae & & \\
\hline & Clavigerinae & & \\
\hline & Scaphidiidae & & \\
\hline & Scydmaenidae & & \\
\hline
\end{tabular}

(1) The classical system is arranged mainly based on Sharp and Muir (1912), Bemhauer and Schubert (1910, 1911, 1912, 1914, 1916) and Bernhauer and Scheerpeltz (1926).

(2) The French system is arranged based on Jeanne1 and Jarrige (1949) and Coiffait (1972).

(3) The Lawrence-Newton system is arranged based on Lawrence and Newton (1982)

among Bledius, the Osoriinae and the Oxyporid-group is wrongly used for classification in the classical system.

Secondly, the Pinophilini (Paederinae) are placed next to the Euaesthetinae 
probably due to the overall similarities in the classical system. The Euaesthetinae (Edaphus, Euaesthetus and so on) and Pinophilini (Palaminus and so on) are similar to each other in the body being elongate and subparallel-sided and the body color being yellowish to yellowish brown. However, considerable morphological gaps are clearly present between the Paederinae and the Euaesthetinae concerning the structures of the tentorium, prothorax and so on. The Paederinae and Euaesthetinae are actually the evolved members of the Staphylinid- and Oxyporid-groups, respectively, and apparently remote from each other.

In addition, the close relationships among the Euaesthetinae, Leptotyphlinae and Pselaphids are not reflected in the classical system. Namely, the Pselaphids are treated as the independent family, leaving the former two subfamilies in the Staphylinidae.

The above-mentioned treatments in the classical system cannot be considered to be reasonable from the viewpoint of phylogenetic systematics, so that the classical system is not accepted here as the adequate one.

2. French system. Paulian (1941) extensively studied the larval morphology in the Staphylinoidea and classified them into five groups 1) Staphylinomorphes : Staphylininae and Paederinae, 2) Aléocharinomorphes: Hydraenidae, Hydroscaphidae, Catopidae, Leiodidae, Leptinidae, Ptiliidae, Proteitae, Omaliitae, Piestitae, Oxytelitae, Tachyporitae, Habroceritae, Stenitae, and Aleocharitae, 3) Oxyporitae, 4) Scaphidiidae, Silphidae, Necrophoridae and Necrodidae, and 5) Scydmaenidae. He did not examine the Pselaphidae and Micropeplinae. Unfortunately, he classified the Staphylinoidea by grade-classification. The concepts of the Staphylinomorphes and Aléocharinomorphes were adopted by the succeeding French entomologists, but the concepts had become used strictly for the Brachelytra or Staphylinidae. Jeanne1 and Jarrige (1949) classified the Brachelytra into three groups :1) Silphidae and Scaphidiidae, 2) Aléocharomorphes: Pselaphidae, Scydmaenidae, Aleocharidae, Oxytelidae, and Stenidae, and 3) Staphylinomorphes : Staphylinidae. And then Coiffait (1972) divided the Staphylinidae into three groups : 1) Staphylinomorpha : Staphylinidae (Leptotyphlinae, Euaesthetinae, Paederinae, Xanthblininae and Staphylininae), 2) Aleocharomorpha : Micropeplidae, Stenidae, Oxytelidae, Tachyporidae, Trichophyidae, Habroceridae, Hypocyptidae and Aleocharidae and 3) Oxyporidae.

The Staphylinomorpha and Aleocharomorpha are defined based on two characters, the maxillary structure and the number of the segments of the antenna at the larval stage. The former group is defined by the maxilla with reduced lacinia and the antenna 4-segmented, and the latter by the maxilla with developed lacinia and the antenna 3-segmented. Of these conditions, the occurrences of the maxilla with reduced lacinia and the antenna 3-segmented may be attainable through parallel evolution in the Staphylinomorpha and Aleocharomorpha, respectively. On the other hand, the occurrences of the maxilla with developed lacinia and the antenna 4-segmented are based on symplesiomorphies in the Aleocharomorpha and Staphylinomorpha, respectively. So the French system cannot be accepted as the reasonable one.

3. Lawrence-Newton system. Lawrence and Newton (1982) recently set forth a 
higher classification system of the Brachelytra in outline. According to them, the Brachelytra (including Dasyceridae) are divided into four major groups :1) Omaliine group : Omaliinae, Microsilphinae, Empelinae, Neophoninae, Proteininae, Dasyceridae, Micropeplidae and Pselaphidae ;2) Tachyporine group : Pseudopsinae, Phloeocharinae, Tachyporinae, Trichophyinae, Habrocerinae and Aleocharinae ; 3) Oxyteline group : Piestinae, Osoriinae, Oxytelinae and Scaphidiidae ; and 4) Staphylinine group : Oxyporinae, Megalopsidinae, Steninae, Euaesthetinae, Leptotyphlinae, Paederinae, Staphylininae, Scydmaenidae and Silphidae.

This system is drastically different from the classical one. In grouping the members of the Brachelytra, they used the following characters :1) atrophy of spiracles of abdomen, 2) abdominal glands, 3) predatory behavior, 4) feeding habits and 5) mode of digestion. They actually paid special attention to the ecological characters as well as morphological ones in which the derived conditions are easy to occur independently. As these characters are difficult to phylogenetically evaluate, the four groups defined by using such characters may not be considered as natural ones. Therefore, the Lawrence-Newton system cannot also be accepted as the adequate one from the phylogenetic viewpoint.

\section{Higher classification newly proposed}

As shown above, each of three higher classification systems of the Brachelytra proposed by previous workers proved to be unreasonable from the viewpoint of phylogenetic systematics, so a higher classification system of the Brachelytra is newly proposed here. It is documented by the large number of autapomorphies and underlying autapomorphies discussed above. In my opinion, the section Brachelytra is divided into the six families listed below.

Section Brachelytra Jeanne1 and Paulian 1944

1. Family Silphidae.

2. Family $\mathbf{O}$ xytelidae sensu novo (= Oxytelid-group).

This family includes the following 8 subfamilies : Oxytelinae, Pseudopsinae, Osoriinae, Piestinae, Micropeplinae, Proteininae, Metopsiinae and Omaliinae.

3. Family Staphylinidae sensu novo (= Staphylinid-group).

This family includes the following 14 subfamilies : Tachyporinae, Phloeocharinae, Habrocerinae, Trichophyinae, Staphylininae, Xantholininae, Paederinae, Hypocyptinae, Pygosteninae, Termitodiscinae, Trilobitideinae, Mimanommatinae, Trichopseniinae and Aleocharinae.

4. Family $\mathbf{O}$ xyporidae sensu novo (= Oxyporid-group).

This family includes the following 11 subfamilies : Oxyporinae, Megalopininae, Steninae, Euaesthetinae, Leptotyphlinae, Faroninae, Euplectinae, Batrisinae, Bythininae, Pselaphinae and Clavigerinae.

5. Family Scaphidiidae. 
6. Family Scydmaenidae.

\section{Acknowledgements}

I wish to express my hearty thanks to Prof. Y. Hirashima and Assoc. Prof. K. Morimoto of the Entomological Laboratory, Faculty of Agriculture, Kyushu University for their kind guidance and encouragement.

My cordial thanks are due to Dr. S. Uéno (National Science Museum, Tokyo), Dr. A. F. Newton (Museum of Comparative Zoology, Harvard University, USA), Assoc. Prof. Y. Watanabe (Tokyo University of Agriculture, Tokyo), and Mr. Y. Shibata (Tokyo) for their kind advice and helpful suggestion on my study of the superfamily Staphylinoidea. I am grateful to Dr. 0. A. Saether (Museum of Zoology, University of Bergen, Norway) for his kindness in giving me the information concerning the underlying autapomorphy and underlying synapomorphy.

I am also indebted to Dr. 0. Tadauchi, Miss C. Okuma, Messrs. T. Goto, N. Koda and K. Ogata (Kyushu University) for their kindness in various ways in the course of this study.

\section{References}

Bemhauer, M. \& 0. Scheerpeltz, 1926. Staphylinidae VI. In Junk \& Schenkling, Coleopterorum Catalogus, W. Junk, Berlin, (82): 499-988.

— \& K. Schubert, 1910. Staphylinidae I. In Junk \& Schenkling, Ibid., (19) : 1-86.

— \& - 1911. Staphylinidae II. In Junk \& Schenkling, Ibid., (29) : 87-190.

___ \& — 1912. Staphylinidae III. In Junk \& Schenkling, Ibid., (40) : 191-288.

$-\&-$, 1914. Staphylinidae IV. In Junk \& Schenkling, Ibid., (57) : 289-408.

—_ \& 1916. Staphylinidae V. In Junk \& Schenkling, Ibid., (67) : 409-498.

Blackwelder, R. k., 1942. Notes on the classification of the Staphylinid beetles of the groups Lispini and Osoriinae. Proc.U.S. nat. Mus., 92 (3140) : 75-90.

Cameron, M., 1930. The fauna of British India, including Ceylon and Burma. Coleoptera Staphylinidae 1. Taylor \& Francis, London. 471 pp.

Coiffait, H., 1972. Coléoptères Staphylinidae de la Région Paléarctique Occidentale. Généralités, sous-familles: Xantholininae et Leptotyphlinae. Suppl.Nouv. Rev. Ent., 2 (2). ix +651 pp.

\& F. Saiz, 1968. Les Staphylinidae (sensu lato) du chili. Biol. Amér. Austr., $4: 339-468$.

Crisci, J. V. \& Stuessy, T. F., 1980. Determining primitive character states for phylogenetic reconstruction. Syst. Bat., 5: 112-135.

Crowson, R. A., 1938. The metendosternite in Coleoptera : a comparative study. Trans. R. ent. Soc. Lond., $87: 397-416$.

, 1955. The natural classification of the families of Coleoptera. Reprint 1967. E. W. Classey. $214 \mathrm{pp}$.

Erichson, W. F., 1839-1840. Genera et species staphylinoruminsectorum coleopterorum familiae. Berlin. 954 pp.

Freude, H., K. W. Harde \& G. A. Lohse, 1964. Die Käfer Mitteleuropas 4. Staphylinidae I. Goeke \& Evers, Krefeld. 264 pp.

Hennig, W., 1965. Phylogenetic systematics. Ann. Rev. Ent., $10: 97-116$.

, 1966. Phylogenetic systematics. University of Illinois Press, Urbana. 263 pp.

Herman, L. H., 1975. Revision and phylogeny of the monogeneric subfamily Pseudopsinae for the 
world (Staphylinidae, Coleoptera). Bull. Am. Mus.nat.Hist., 155 : 241-318.

Jeannel, R., \& J. Jarrige, 1949. Coléoptères Staphylinides (première série). Arch. Zool. Exp. Gén., $86: 255-392$.

— \& R. Paulian, 1944. Morphologie abdominale des Coléoptères et systématique de l'order. Revue fran. Ent., $11: 65-110$.

Lawrence, J. F., \& A. F. Newton, 1982. Evolution and classification of beetles. Ann. Rev. Ecol. Syst., $13: 261-290$.

Matsuda, R., 1970. Morphology and evolution of the insect thorax. Mem. ent. Soc. Canada, (76). 431 pp.

Newton, A. F., 1982. Redefinition, revised phylogeny, and relationships of Pseudopsinae (Coleoptera, Staphylinidae). Am. Mus. Nov., (2743) : 1-13.

Paulian, R., 1941. Les premiers états des Staphylinoidea (Coleoptera). Etude de morphologie comparée. Mém. Mus. nat. Hist. nat. Paris, 15. 361 pp.

Saether, 0. A., 1979. Underlying synapomorphies and anagenetic analysis. Zool.Scr., 8: 305-312.

- 1983. The canalized evolutionary potential : inconsistencies in phylogenetic reasoning. Syst. Zool., 32: 343-359.

Seevers, C. H., 1955. A revision of the tribe Amblyopinini: Staphylinid beetles parasitic on mammals. Field. Zool., 37 : 211-264.

— \& H. S. Dybas, 1943. A synopsis of the Limulodidae (Coleoptera). A new family proposed for myrmecophiles of the subfamilies Limulodinae (Ptiliidae) and Cephaloplectinae (Staphylinidae). Ann. ent. Soc. Am., 36 : 546-586.

Sharp, D. \& F. Muir, 1912. The comparative anatomy of the male genital tube in Coleoptera. Trans. ent. Soc. Lond., 1912: 477-642.

Tichomirova, A. L., 1968. Staphylinid beetles of Kara-Tau (Coleoptera, Staphylinidae). In B. B. Rohdendorf, ed., Zhurskie Nasekomie Keratau, Nauka, Moscow. P. 139-154. (In Russian).

Watrous, L. E., and Q. D. Wheeler, 1981. The out-group comparison method of character analysis. Syst. Zool., $30: 1-11$. 